\title{
Web-based applications to develop students' creativity in English for specific purposes
}

\author{
Iryna Simkova ${ }^{1}$, Oleksandra Bondarenko², Lina Bielovetska ${ }^{3}$ \\ ${ }^{1,2}$ Department of English Language for Humanities, National Technical University of Ukraine "Igor Sikorsky Kyiv \\ Polytechnic Institute", Ukraine \\ ${ }^{3}$ Department of Foreign Languages and Professional Communication, Volodymyr Dahl East Ukrainian National \\ University, Ukraine
}

\begin{tabular}{l} 
Article Info \\
\hline Article history: \\
Received Nov 29, 2020 \\
Revised Mar 25, 2021 \\
Accepted Apr 19, 2021 \\
\hline
\end{tabular}

Keywords:

Creative thinking

Creativity

Distance learning

English for specific purposes

Web-based applications

\begin{abstract}
This paper investigates the implementation of web-based applications to develop students' creative thinking skills in English for Specific Purposes. The paper explores the role of web-based applications during creativity development in English for Specific Purposes classes. The attention is paid to the analysis of organizational levels of creative thinking development and concepts of creativity. This paper discusses how to achieve creative thinking during distance learning in English for Specific Purposes classes. The sample was 310 bachelor students from two Ukrainian universities. The sample was selected on the basis of the stratified sampling technique. The instruments were used F-test, the Likert-type scale test, and interviews. The study presents the results gained from interviews with Ukrainian students and results of creativity tests passed by students. The examples of tasks aimed at creative thinking achievement during distance learning in English for Specific Purposes classes are given. A comparative analysis of results has allowed emphasizing the positive experience of two Ukrainian universities, which can be implemented in future distance learning in the higher institutions located in other regions of Ukraine. The findings of this study support the idea that the development of creative thinking skills during the distance learning of bachelor students of different specialism can be intensified with the selection of proper web-based applications.
\end{abstract}

This is an open access article under the CC BY-SA license.

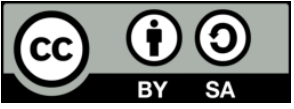

\section{Corresponding Author:}

Iryna Simkova

Department of English Language for Humanities

National Technical University of Ukraine "Igor Sikorsky Kyiv Polytechnic Institute"

37 Peremogy Avenue, Kyiv, 03056, Ukraine

Email: isimkova@ukr.net

\section{INTRODUCTION}

In the age of globalization specialists in different fields constantly solve non-standard tasks in an uncertain and contradictory environment. Through the development of creativity, future professionals resolve problematic situations, actively and constructively transforming them. Creativity is one of the basic human abilities, without which the progress of mankind is impossible [1].

The current development of modern educational technologies and web-based applications makes it possible to use them in practice for educational purposes during distance learning. However, until recently in Ukraine, some teachers claim that there were not so many applications that would enhance the development of creativity. During distance learning, the teachers in higher institutions of Ukraine offered to students, mainly, the reproductive level of its use. Such an approach virtually eliminates the abilities to develop skills 
of creativity during English for Specific Purpose (ESP) classes due to the lack of the possibility of modifying the applied educational applications. Therefore, the well-known role of the teacher as executor of normative training must be replaced by the role of the teacher as a teacher of innovative learning [2]. As a result, the properly selected and high-quality web-based applications can help in updating educational materials and intensify the achievement of creativity in the educational process.

In the literature there seems to be no general definition of the term "creativity", thus in our study concept of creativity can be considered in three relatively independent planes as creative thinking (within the framework of cognitive processes, as thinking aimed at creating new knowledge or masterpiece), the personal characteristic of a student (it is present as a special typological feature of character), and creative product or work (something that is originally and qualitatively new, and possesses the internal (feeling of satisfaction) and external quality criteria: aesthetics in art or technical advantage in the scientific invention).

Jaarsveld, et al. [3] investigate the development of creativity that consists of two phases: primary creativity as a general creative ability and specialized creativity associated with a specific field of activity. The development of primary creativity, carried out in the secondary school or vocational education periods, has been considered in numerous studies [4], [5]. In previous research [6], [7], the authors investigated the conditions for the development of specialized creativity in the higher institution period.

The most significant observation for the history of creative psychology was done by Guildford in 1945 followed by other scientists who determined creative thinking as divergent thinking [8]. Thus, Guildford pointed to the fundamental difference between the two types of mental operations: convergence and divergence. A feature of divergent thinking is the willingness to put forward equally correct ideas concerning the same object.

In this paper, we consider the term divergence as the ability to see one object from different faces or find a couple of different ways to solve a problem. Divergent thinking is the exact opposite of convergent thinking. It associates with algorithmic and linear thinking, which is traditionally taught at higher institutions. It is divergent thinking that allows students to design creative work, to see unexpected associative links, and come to unplanned results.

Mednik according to Benedek and Neubauer [9] considering the concept of creative activity believes that division of cognitive process into convergent and divergent components is inadequate. According to Cropley [10] the decline in the development of creativity can be eliminated at any age using special training or selected web-based applications.

Stezo [11] suggests that students who experienced usual learning in classes demonstrate a higher level of creative thinking development than students who experienced distance learning. It is claimed that distance learning reduces the level of creative activity due to the algorithmizing and formalizations of tasks. But our point is that level of creative thinking may be increased due to the changing of instructions of tasks with the help of information applications implementations. Web-based application implementation aims to activate creative thinking by changing the attitude of students to the tasks. Thus, the primer stage is the motivation of creativity and the secondary stage is the performance activity itself. So, the implementation of web-based applications during ESP classes provides an environment for the creative opportunities for the manifestation of the creative abilities of students.

In connection with the gradual transformation of the traditional learning and teaching (during which students are only provided with information) into a qualitatively new type of learning and teaching in which a student changes the role of a passive consumer of knowledge and outdated information to an active role of a creative person, the higher institutions stand up for the modification of traditional methods of teaching ESP and the formation of new priorities [12], [13]. A recent review of the literature on this topic [14]-[16] found that creative thinking development can be implemented at different organisational levels as shown in Table 1.

Table 1. Different organisational levels of creative thinking development

\begin{tabular}{|c|c|c|c|c|}
\hline Mega-Level & Macro level & Meso-level & Micro-level & Nano-level \\
\hline $\begin{array}{l}\text { The creation of a set of } \\
\text { measures at the state } \\
\text { level contributes to the } \\
\text { design of the state } \\
\text { policy and regulations } \\
\text { to increase creative } \\
\text { thinking development }\end{array}$ & $\begin{array}{l}\text { The motivation of the } \\
\text { audience (students, } \\
\text { teachers, PhDs, etc) in } \\
\text { the regions based on } \\
\text { the interaction of } \\
\text { educational institutions } \\
\text { and cultural } \\
\text { institutions. }\end{array}$ & $\begin{array}{l}\text { An increase in the } \\
\text { proportion of students } \\
\text { (classes) motivated for } \\
\text { creative thinking } \\
\text { development through } \\
\text { educational and } \\
\text { specially organized } \\
\text { events with the support } \\
\text { of departments of the } \\
\text { higher institutions. }\end{array}$ & $\begin{array}{l}\text { The organisation of } \\
\text { specific activities } \\
\text { aimed at the } \\
\text { development of } \\
\text { creative thinking based } \\
\text { on properly selected } \\
\text { information } \\
\text { applications. }\end{array}$ & $\begin{array}{l}\text { The design of } \\
\text { individual tasks } \\
\text { relevant to student's } \\
\text { professional activities } \\
\text { that motivate the } \\
\text { creative thinking } \\
\text { development in ESP } \\
\text { classes. }\end{array}$ \\
\hline
\end{tabular}


In the literature, there are many examples [17]-[19] aimed at studying the features of the development of creativity in the learning process. Few studies [20], [21] have been published on the issues of the development of students' creativity within the problem-solving approach in the classroom. Botella, Nelson, and Zenasni have been widely investigated the development of students' creative abilities, especially the use of a creative process diary in educational and extracurricular activities [22].

Modern Ukrainian society faces many strategic tasks such as modern reforms and innovative development of education, in this condition the creative thinking and finding of non-standard solutions are recognized as being the most important personal features of future specialists. The education system is a crucial element in the process of creative thinking development. The web-based applications used during ESP classes can solve the main tasks such as to reveal the creative abilities of students, to prepare a student to be ready to use creativity in a high-tech life and changing world, to react creatively to difficult professional situations.

Most of the applications (Google Meets, Microsoft Teams, Skype, Zoom, Kahoot, ClassDojo, Evernote, and Joinpd) are based on the ability to accompany a video conferencing session with a synchronized series of demos and tools. As a rule, in each such application, there is the possibility of presenting slides and drawing (sometimes joint) on the chalkboard. After detailed analysis, they still differ from each other and provide very dissimilar sets of functions and tools. At the same time, many important techniques and web-based applications that could help to develop creative thinking during ESP class remain outside the scope of consideration.

There are no concerns that aspects of the traditionally considered structure of lesson that is present in most human-to-human interaction cannot be automatically transferred to the classes belong to the humanto-machine-to-human interaction. Thus, the environment created in higher institutions in Ukraine can facilitate or hinder the development of a creative personality. The development of students' creativity must be considered during the process of psychological and pedagogical support since it is a resource that can be created to enrich the social environment that contributes to the manifestation and development of the creative thinking of students.

In 2020 due to lockdown, almost all higher institutions in Ukraine provide distance learning. As a result, many students and teachers of higher institutions who got used to working in usual classes and are displaced to virtual classes feel stressed and unhappy. It was decided that the implementation of properly selected web-based applications during ESP classes is best for this study in order to reduce the level of stress experienced by students and teachers and increase the level of creativity. The idea is in line with essentially the same as that used by Martins [23] with some modifications.

The implementation of web-based applications during ESP classes students promotes the introduction of specially selected exercises and tasks to develop creative thinking abilities. This also provides students and educators with theoretical and practical material to overcome stereotypes and thinking patterns. The objectives of such kind of learning are to promote the development of creative thinking abilities (fluency, flexibility, originality, and elaboration) [24]; to increase the motivation of students for independent research and creative activity; to help in the disclosure and development of the creative potential of the teachers themselves. This raises many questions regarding whether Torrance Tests of Creative Thinking (TTCT) should be used for measuring the creativity of students [25], but this suggestion suffers from a plethora of pitfalls. The properly selected web-based applications in ESP classes contribute to the development of creativity, creative activity, and aimed at improving such skills as analysis, generalization, synthesis, and information processing.

The systematical implementation of properly selected web-based applications during ESP classes aimed at the development of creative skills because they help: 1) To go beyond one subject; 2) To shift the emphasis in learning from perception to creative expression learners in activities; 3) To promote creative tasks in classes; 4) To increase the interaction with students; 5) To combine basic and creative methods of education.

It is important to note that the knowledge, skills, and abilities acquired in ESP classes are successfully transferred by students to other academic subjects and into future professional activities. The selection of web-based applications as a complex of joint actions of teachers of different subjects aimed at developing creative thinking skills and abilities of students based on finding common topics, studied objects and phenomena, the unity of didactic principles and goals. The set of chosen web-based applications vary according to the specialism of students and their year of studying.

Achievement of high results in the development of creative thinking of students during ESP classes with the implementation of web-based applications is more possible only when designing integrated developmental education systems. The application of an integrated approach allows for the transmission of the content of the ESP course to a wider plane, creating opportunities for developing creativity and other skills belong to Communication, Collaborative, Critical thinking, and Creativity [26]. Integrated learning 
contributes to the design of a special creative lesson atmosphere based on cooperation and co-creation of both teachers and students, and students in groups and in peers.

Creative thinking is a guarantee of mankind's progress because it represents a means of assisting society in the resolve of problematic situations, their actively and constructively transformation. So, the present paper aims to promote the development of creative thinking in students of different specialism during ESP courses with the implementation of web-based applications and integrated learning. For this purpose, we will investigate the concept of creative thinking development, implement the type of activities promoted the development of students' creative thinking into the ESP classes; interview students who participated in the experimental study from two Ukrainian universities; validate finding regarding creative thinking skills development during ESP classes with the implementation of web-based applications.

\section{RESEARCH METHOD}

To achieve the goals of the study, complex interconnected methods of scientific research has been used. The theoretical methods used in the paper are the generalization of psychological and pedagogical literature to consider the main features of creativity; the comparative analysis to stipulate the different levels of creative thinking promotion; the terminological analysis to define the key concepts of creativity, the content analysis of tasks proposed during ESP classes with the implementation of web-based applications.

The empirical methods used in the study are the quantitative and qualitative analysis of interviews with Ukrainian students; Fisher's Exact Variance Test (F-test) for verification of results [27], and the Likerttype scale for the assessment of the performance of the assignments [28]. Data received during the interviews are based on the student's personal feelings and personal self-evaluation. To be more precise about their personal feeling concerning the creative thinking skills development we propose students to pass the Torrance Tests of Creative Thinking (TTCT), Guilford's Alternative Uses Test, or Wallach and Kogan's creative thinking tests) that include tasks for divergent thinking assessment as well as problem-solving skills. In a general context, there are many different tests for creative thinking assessment but listed above being regarded as among the more reliable [29].

The study was carried out among a sample of 310 bachelor students of different specialism from two Ukrainian universities (the National Technical University of Ukraine "Igor Sikorsky Kyiv Polytechnic Institute" and Volodymyr Dahl East Ukrainian National University). All of the participants recruited for this study were aged between 18 to 20 years old ( 57 female and 253 male). The whole population of the study is 600 bachelor students of different specialism. The sample was selected on the basis of the stratified sampling technique. The criteria for selecting a sample were: students belong to the second or third year of study where ESP classes are conducted with the implementation of such information applications as Zoom, Microsoft Teams, and Google Meets.

The effectiveness of the implementation of the web-based applications in support of creative thinking skills development during ESP classes was estimated both based on the interview results of students (personal dynamics) and based on the results of creative thinking skills tests. Interviews were semi-structured and performed informally.

The semi-structured interview was chosen based on the idea that it providing an opportunity to explore additional information about students' feelings concerning their creative thinking skills development relevant to the study. The interview takes not more than five minutes for each student. Table 2 presents the example of questions proposed to students that are quite similar to a modified 5-point Likert-type scale.

Table 2. The example of questions proposed to students during the semi-structured interviews

\begin{tabular}{|c|c|c|c|}
\hline \multicolumn{4}{|c|}{ When you are participating in problem-solving tasks in ESP classes how can you evaluate your solutions and answers } \\
\hline Originality & Flexibility & Fluency & \\
\hline $\begin{array}{l}\text { Where } 0 \text { means not original } \\
\text { and } 5 \text { means highly original }\end{array}$ & $\begin{array}{l}\text { Where } 0 \text { means not flexible } \\
\text { and } 5 \text { means highly flexible }\end{array}$ & $\begin{array}{l}\text { Where } 0 \text { means not fluent } \\
\text { and } 5 \text { means highly fluent }\end{array}$ & $\begin{array}{l}\text { Where } 0 \text { means not elaborated } \\
\text { and } 5 \text { means highly elaborated }\end{array}$ \\
\hline
\end{tabular}

As was mentioned previously to verify the interview results of the creative thinking development of students during ESP classes with the implementation of properly selected web-based applications, Fisher's Exact Variance Test (F-test) was used. Data management was performed with XLSTAT by Addinsoft [30]. The F-test was chosen because it is one of the most effective ways to verify the valuable results of the creative thinking development of students during ESP classes with the implementation of web-based applications.

Table 3 demonstrates the initial findings for the F-test application. It shows the interview and test results obtained from students before and after the distance learning during ESP classes with the 
implementation of web-based applications where teachers provided types of exercises promoting creative development. We consider the results given by students before they start distance learning in ESP class to be sample 1, and results presented by students three months after they started distance learning in ESP class to be sample 2 .

We have enunciated statistical hypotheses that enable the calculation of the results received before and after distance learning during ESP classes with the implementation of properly selected web-based applications. The statistical hypotheses assume the null (H0) and alternative (Ha) hypotheses:

Sample 1 represents $\mathrm{H} 0$ where the results indicated that the number of students who developed their creative thinking skills before the start of ESP classes with the implementation of properly selected webbased applications is higher than the number of students, who developed the higher level of their creative thinking skills after the start of ESP classes with the implementation of properly selected web-based applications.

Sample 2 represents Ha where the results indicated that the number of students who developed their creative thinking skills before the start of ESP classes with the implementation of properly selected webbased applications is lower or equal to the number of students, who developed the higher level of their creative thinking skills after the start of ESP classes with the implementation of web-based applications.

The obtained results show that only twenty students consider that they develop their creative thinking skills before they start ESP classes with the implementation of properly selected web-based applications. Thus, we put twenty to the first higher column (quantity of students-before). Two hundred ninety students develop their creative thinking skills after they start ESP classes with the implementation of properly selected web-based applications. Thus, we put 290 in the lower column (quantity of students-after). For the sake of simplicity, we use (1) where $\varphi=$ central angel value; $p=$ percentage value.

$$
\begin{aligned}
& \varphi=2 \arcsin \sqrt{ } p \\
& \varphi^{*} 1=2 \arcsin \sqrt{ } \frac{20}{290}=0.54 \\
& \varphi^{* 2}=2 \arcsin \sqrt{ } \frac{290}{310}=2.58
\end{aligned}
$$

Using (2) we can find the empirical F-test $\varphi^{*}$ emp:

$$
\varphi^{*} \mathrm{emp}=\left(\varphi^{*} \max -\varphi^{*} \min \right) \sqrt{ } \frac{\mathrm{n} 1 \cdot \mathrm{n} 2}{\mathrm{n} 1+\mathrm{n} 2}
$$

Where:

$\varphi^{*} \max$ represents angle corresponding to bigger percentage $\varphi *$ min represents angle corresponding to smaller percentage $\mathrm{n} 1$ represents quantity of students in sample 1 $\mathrm{n} 2$ represents quantity of students in sample 2

$$
\text { In our paper } \left.\varphi^{*} \mathrm{emp}=2.58-0.54\right) \sqrt{ } \frac{310 \cdot 310}{310+310}=25.4
$$

The table with critical value fraction $\varphi^{*}$ crit demonstrates critical values of F-test for variances (3)

$$
\begin{array}{r}
\varphi^{*} \mathrm{crit}=1.64(\mathrm{p} \geq 0.05) \\
2.31(\mathrm{p} \geq 0.01)
\end{array}
$$

\section{RESULTS AND DISCUSSION}

When analyzing the result obtained after the initial cohort of 310 subjects completed the interview, we found significant changes in all indicators of creativity. When analyzing the indicators of creativity (fluency, flexibility, originality, and elaboration), the results of sample 1 and sample 2 were compared. In compliance with a critical value fraction $\varphi^{*}$ crit, our empirical value belongs to the Significant Zone of F-test which is why the results obtained in our study are significant. The number of participants who acquired creative thinking skills development in sample 2 is higher than in sample 1.

We found much higher values for creative thinking skills development with respect to those reported by Piffer [31]. Our results have been confirmed with the explanations. As was presented before most respondents (290 students) felt that with the introduction of ESP classes with the implementation of web- 
based applications they develop their skills and abilities in creative thinking. In Table 3, we have divided the empirical frequencies of students' samples following two variances: effect present and effect absent.

Table 3. The results of empirical frequencies of the sample

\begin{tabular}{cccccc}
\hline Results samples & $\begin{array}{c}\text { Effect present } \\
\text { Quantity of students }\end{array}$ & $\%$ & $\varphi$ & $\begin{array}{c}\text { Effect absent } \\
\text { Quantity of students }\end{array}$ & $\begin{array}{c}\text { The total quantity } \\
\text { of students }\end{array}$ \\
\hline Sample 1 & 20 & 7 & 0.54 & 290 & 310 \\
Sample 2 & 290 & 93 & 2.58 & 20 & 310 \\
\hline
\end{tabular}

Comparing the critical value results with the empirical value results is assisted with the axe of significant zones and can be demonstrated in Figure 1.

$\varphi^{*} \operatorname{crit}(0.01)<\varphi^{*} \mathrm{emp}$

$2.58<25.4$

Insignificant Zone

Significant Zone

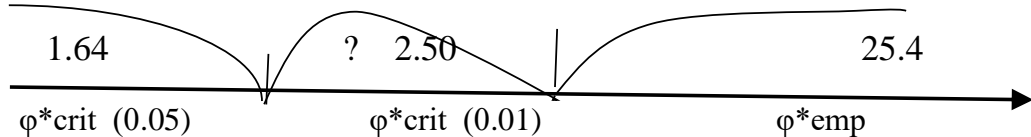

Figure 1. Graphical presentation of F-test with significant and insignificant zones

The study results demonstrate that in the process of ESP classes with the implementation of properly selected web-based applications for the development of creative thinking, students experienced a change in the originality criterion. Analysis of the interview results of the study made it possible to identify significant differences between sample 1 and sample 2. An increase in the number of students of different specialism in the second year of study with a high level of flexibility and a decrease with an average and low level. The single most marked observation to emerge from the data comparison was that with the introduction of the properly selected web-based applications in the experimental groups, students with a high level of creativity development accounted for $7 \%$, the middle level was $26 \%$, and the low level was $67 \%$. At the end of the experiment, the number of students with a high level of creativity was $66 \%$ of the total, the middle level was $27 \%$, the low level was $7 \%$. It is interesting to note that at the end of the experiment, the percentage of students with a middle level of creative skills development increased only by $1 \%$ compared to the beginning of e-learning. Contrary to our expectations, we did not find a significant difference in the middle level of results before and after the experiment. This apparent lack of difference can be attributed to the reason mentioned during interviews by students themselves comment their little progress with the low level of attendance.

The results of our study are consistent with the ideas expressed by Sternberg [32] and Newton [33]. The purposeful development of successful intelligence and creative thinking skills in students can lead to the achievement of characteristics belong to creativity.

According to Karakoc [34], students' age (18-24) is a sensitive period in the development of both creative skills and critical thinking skills, influencing the formation of the personality as a whole. They strive for self-improvement, independence, abandonment of stereotypes, however, insufficiently adequate judgments about what is happening to make the students be exposed to random influences. Researchers [35], [36] point out the need for purposeful development of creativity in student age, the creation of conditions for its development. Representatives of humanistic psychology [37], [38] distinguish external (ensuring psychological safety, lack of evaluation) and internal (openness of the individual to new experience, internal positive assessment of creativity) conditions. Guildford in 1950 [8] and Torrance in 1962 [39] propose such conditions of creative thinking development as a favorable atmosphere in the class, fostering of students' awareness of the value of the creative skills in their personality, and providing a pattern of creative behavior in the professional environment. These findings correlate favorably with McGregor [40] and further support the idea that creativity is satisfactorily developed through the problem-solving approach. 
Any kind of self-expression in a class during the performance of tasks aimed at creative thinking development can be considered as a creative activity, if it is subject to the rules of class interaction, and if students expressing their ideas do not hurt at the same time the honor and dignity of the classmates. As already mentioned, the products of creative activity are valuable primarily for the members of all teams or for those participants who are especially involved in the assignment process.

Special attention must be paid to the fact that the result or product of creative activity is of particular value for classmates, and that spectrum of emotions and discoveries that accompanied the creative activity of the product in the process of completing an assignment or task gains significant value. For example, Figure 2 illustrates the example of assignments that the authors of this study propose to the students of the third year of study specialized in design.

Task Name: ORIGINAL USE

Task Description: Imagine that your group will participate in the International conference of

Innovations. Looking around and find some of the following things:

- BLOWN LIGHT BULBS

- plastic bottles

- aluminumbeverage cans

Work in group of 4-5, time 10 minutes. Your task is to to create and present as many variable and feasible kinds of original use of the given usual things as possible. The winner will be a team with the most quantity of feasible ideas.

Figure 2. The examples of students' assignments to develop creative thinking during ESP classes with the implementation of properly selected web-based applications

The assignment can be performed differently due to the specialism of students and due to the list of things. The list of things is changed as well due to the specialism of students. For instance, an assignment may be presented in drawing by members of a team with no special education in art or design. The presentation of the task may be saturated with innovative thoughts and perceived by other teams as a source of positive emotions. The team presents the ideas may feel the same or may experience their range of emotions and reactions to the drawing presented by the participant or remain indifferent.

It often happens that the attitude towards the task presentations changes during the discussion dedicated to the presentation of ideas. It also happens that the presentation of a task (drawings, simulation, draft) is done by one of the participants has a greater impact on other students than the author himself/herself. An unexpected is the fact that the presentation of a task, taken out of the context of the performance, can also be perceived as the presentation of a task evoking a certain range of similar emotions and sensations from people unfamiliar either with the content of tasks or with the authors.

It should be noted that in the process of step-by-step work with the pattern, some teams gradually improve the quality and depth of the idea, and the presentations become more emotionally rich. They begin to reflect the valuable aspects of the author's personality in each team, their feelings and emotions, and fields of professional interests. Even though these results differ from some published [41], they are consistent with those results concerning measuring creativity [42].

Creativity was assessed to creative thinking ability, self-reported ideational behavior, and selfreported creativity. Creative thinking during task performance and presentation can be assessed through three items of the task of the original use (blown light bulbs, plastic bottles, aluminium beverage cans). The task duration was 3 minutes for each item.

The fluency, flexibility, originality, and elaboration of task presentations performed by Team 1 were scored by the rest three groups (Team 2, Team 3, and Team 4) on a modified 5-point Likert-type scale [43], [44] ranging from 0 ("not original", "not fluent", "not flexible" or "not elaborated) to 5 ("highly original", "highly fluent", "highly flexible" or "highly elaborated" respectively). Acar, Burnett, and Cabra [45] noted that originality was the strongest correlate of creativity. Our results seem to confirm their observation, in fact, in our study, the originality ratings of all ideas within a task were added up to compute a total score of creative thinking. The total score thus reflects the number of ideas generated by students i.e., fluency, ability to be new, interesting, and different i.e., originality. The ability to think about things in a different way i.e., flexibility, and the ability to improve, rework, and embellish ideas i.e., elaboration. 
The properly selected web-based applications depending on the assignment. As example, for the assignment presented in Figure 2 were selected Breakoutrooms in Zoom for work in groups, Evernote to make notes, and Kahoot to let teams assess the creative thinking of their classmates.

\section{CONCLUSION}

Till the lockdown 2020, the use of web-based applications during ESP teaching is aimed at mastering by students of well-known technologies and techniques for using computer tools and only partially aimed at the development of creativity. To change this situation in the higher institutions in Ukraine, it is necessary to introduce teaching methods aimed at the implementation of creative rather than reproductive activity. It will allow students to master the possibilities of using information technologies and study new methods of using these technologies in professional activities during ESP classes in order to achieve creative thinking in the field of their professional activities. Our work has led us to the understanding that ESP teachers when selecting a proper web-based application should pay attention to the specialism of students, the aim of the assignment, and the criteria of creativity development assessment.

The evidence from this study suggests that the web-based applications selected for use in ESP classes must be relevant to the specifics of the modern stage of scientific and technological progress. In this regard, it is necessary to provide teachers with information about cutting-edge educational web-based applications. We have obtained satisfactory results demonstrating the development of creative thinking skills during the distance learning of bachelor students of different specialism in ESP classes can be intensified with the selection of proper web-based applications.

\section{ACKNOWLEDGEMENTS}

This research was supported by the Department of English Language for Humanities and Faculty of Linguistics, Igor Sikorsky Kyiv Polytechnic Institute and the Department of Foreign Languages and Professional Communication, Volodymyr Dahl East Ukrainian National University, Ukraine.

\section{REFERENCES}

[1] National Education Association, Preparing 21st Century Students for a Global Society: An Educator's Guide to the "Four Cs", 2016.

[2] N. Songkram, "E-learning System in Virtual Learning Environment to Develop Creative Thinking for Learners in Higher Education," Procedia - Social and Behavioral Sciences, vol. 174, pp. 674-679, Feb. 2015.

[3] A. Jaarsveld, M. Fink, D. Rinner, M. Schwab, N. Benedek, and T. Lachmann, "Intelligence in creative processes: An EEG study,” Intelligence, vol. 49, pp. 171-178, 2015.

[4] S. Said-Metwaly, E. Kyndt, and W.V. den Noortgate, "The factor structure of the Verbal Torrance Test of Creative Thinking in an Arabic context: Classical test theory and multidimensional item response theory analyses," Thinking Skills and Creativity, vol. 35, Mar. 2020, doi: 10.1016/j.tsc.2019.100609.

[5] R. E. Beaty, M. Benedek, P. J. Silvia, and D. L. Schacter, "Creative cognition and brain network dynamics," Trends in Cognitive Sciences, vol. 20, pp. 87-95, 2016.

[6] T. C. Kershaw, S. Bhowmick, C. C. Seepersad, and K. Hölttä-Otto, "A decision tree based methodology for evaluating creativity in engineering design," Front. Psychol., vol. 10, 2019, doi: 10.3389/fpsyg.2019.00032.

[7] D. H. Cropley, "Creativity Training," in Creativity in Engineering. Academic Press, 2015, pp. 227-255.

[8] J. P. Guilford, "Creativity," in American Psychologist, vol. 5, no. 9, pp. 444-454, 1950, doi: 10.1037/h0063487

[9] M. Benedek and A. C. Neubauer "Revisiting Mednick's Model on Creativity-Related Differences in Associative Hierarchies. Evidence for a Common Path to Uncommon Thought," The Journal of Creative Behavior, vol. 47, no. 4, pp. 273-289, Nov. 2013.

[10] A. Cropley, "Definitions of Creativity," In M. A. Runco, S. R. Pritzker, Eds., Encyclopedia of Creativity, vol. 1, Academic Press, 2011, pp. 511-524.

[11] E. Stezo, "A comparison of online/face-to-face students' and instructor's experiences: Examining blended synchronous learning effects," Procedia - Social and Behavioral Sciences, vol. 116, pp. 4250-4254, 2014.

[12] M. B. Wieth and A. P. Francis, "Conflicts and consistencies in creativity research and teaching," Teaching of Psychology, vol. 45, pp. 363-370, 2018.

[13] J. C. Kaufman, "Why creativity isn't in IQ tests, why it matters, and why it won't change anytime soon probably," Intelligence, vol. 3, pp. 59-72, 2015.

[14] A. Craft, Creativity and education futures: Learning in a digital age. Stoke-on-Trent: Trentham Books. 2011.

[15] S.B. Kaufman, L.C. Quilty, R.G. Grazioplene, J.B. Hirsh, J.R. Gray, J.B. Peterson, and C.G. DeYoung, "Openness to Experience and Intellect differentially predict creative achievement in the arts and sciences," Journal of Personality, vol. 84, pp. 248-258, 2016.

[16] D. Fasko, "Education and Creativity," Creativity Research Journal, vol. 13, pp. 317-327, 2001.

[17] G. E. Corrazza, "Potential originality and effectiveness: the dynamic definition of creativity," Creativity Research Journal, vol. 28, pp. 258-267, 2016. 
[18] M. Batey, "The measurement of creativity: from definitional consensus to the introduction of a new heuristic framework," Creativity Research Journal, vol. 24, pp. 55-65, 2012.

[19] Ch.-H.Yoon, "A validation study of the Torrance Tests of Creative Thinking with a sample of Korean elementary school students," Thinking Skills and Creativity, vol. 26, pp. 38-50, Dec. 2017.

[20] S. Jaarsveld and Th. Lachmann, "Intelligence and creativity in problem solving: the importance of test features in cognition research,” Front. Psychol., vol. 8, 2017, doi: 10.3389/fpsyg.2017.00134.

[21] R. E. Beaty, E. C. Nusbaum, and P. J. Silvia, "Does insight problem solving predict real-world creativity?" Psychology of Aesthetics, Creativity, and The Arts, vol. 8, no. 3, pp. 287-292, 2014.

[22] M. Botella, J. Nelson, and F. Zenasni, "It is time to observe the creative process: How to use a creative process report diary (CRD)," The Journal of Creative Behavior, vol. 53, pp. 211-221, 2017.

[23] M. de Lurdes Martins, "How to Effectively Integrate Technology in the Foreign Language Classroom for Learning and Collaboration" International Conference on New Horizons in Education, vol. 74, 2015, pp. 77-84.

[24] K. P. Madore, D. R. Addis, and D. L. Schacter, "Creativity and memory: effects of an episodic-specificity induction on divergent thinking," Psychological Science, vol. 26, pp. 1461-1468, Sep. 2015.

[25] L. S. Almeida, M. Ferrando, D. Prieto, and E. P. Oliveira, "Torrance Test of Creative Thinking: The question of its construct validity,” Thinking Skills and Creativity, vol. 3, pp. 53-58, Apr. 2008.

[26] L. Baranovska, L. Morska, I. Simkova, and A. Zasluzhena," Enhancing critical thinking skills of future language scholars in pedagogical courses," Advanced Education, vol. 14, Special Issue, pp. 91-99, May 2020.

[27] W. Navidi, and B. Monk, ISE Elementary Statistics. McGraw-Hill, 2018.

[28] A. Joshi, S. Kale, S. Chandel, and D. Kumar Pal, "Likert Scale: Explored and Explained," Current Journal of Applied Science and Technology, vol. 7, no. 4, pp. 396-403, Jan. 2015.

[29] N. Sosnytska, O. Titova, S. Symonenko, and O. Kravets "Examining the creative potential of engineering students," Modern Development Paths of Agricultural Production. Springer, 2019, pp. 299-307.

[30] XLSRAT by Addinsoft. Two-sample comparison of variances, XLSRAT. [Online]. Available: https://www.xlstat.com/en/solutions/features/two-sample-comparison-of-variances. (accessed Nov. 27, 2020).

[31] D. Piffer, "Can creativity be measured? An attempt to clarify the notion of creativity and general directions for future research," Thinking skills and Creativity, vol 7, no. 3, pp. 258-264, 2012.

[32] R. J. Sternberg, "Teaching for successful intelligence: Principles, practices, and outcomes," Educational and Child Psychology, vol. 20, no. 2, pp. 6-18, 2003.

[33] L. D. Newton and D. P. Newton, Making Purposeful Thought Productive. ICIE, Ulm, 2018.

[34] M. Karakoc, "The Significance of Critical Thinking Ability in terms of Education," International Journal of Humanities and Social Science, Vol. 6, No. 7, pp. 81-84, Jul. 2016.

[35] S. Costa, C. Obara, and F. Broietti, "Critical Thinking in Science Education Publications: The Research Contexts," Int. J. Develop. Res., vol. 10, no. 8, pp. 39438-39448, 2020, doi: 10.37118/ijdr.19437.08.2020.

[36] V. Silber-Varod, Y. Eshet-Alkalai, and N. Geri, "Tracing research trends of 21st-century learning skills," British Journal of Educational Technology, vol. 50, no. 6, pp. 3099-3118, 2019, doi: 10.1111/bjet.12753.

[37] H. Friedman, "Humanistic and positive psychology: The methodological and epistemological divide," The Humanistic Psychologist, vol. 36, pp. 113-126, 2008.

[38] H. Gardner, Intelligence reframed: Multiple intelligences for the 21st century. New York, NY: Basic Books, 1999.

[39] E. P. Torrance, Guiding creative talent. Englewood Cliffs, NJ: Prentice-Hall. 1962.

[40] D. McGregor, "Development of creative thinking," Developing Thinking Developing Learning. Open University Press, 2019, pp. 167-189.

[41] D. K. Simonton, "Big-C versus Little-c creativity: Definitions, Implications, and Inherent Educational Contradictions," in R. A. Beghetto and B. Sriraman, Eds., Creative Contradictions in Education. Springer International, Berne, 2017, pp. 3-19.

[42] S. Said-Meturaly, W. Van den Noortgate, and E. Kyndt, "Approaches to measuring creativity: as systematic review," Creativity, vol. 4, no. 2, pp. 238-275, 2017, doi: 10.1515/ctra-2017-0013.

[43] K. K. Tsang, "The use of midpoint on Likert scale: The implications for educational research," Hong Kong Teachers Centre Journal, vol. 11, pp. 121-130, 2012.

[44] OECD, "Framework for the Assessment of Creative Thinking in PISA 2021 (Third Draft)," in PISA 2021 Creative Thinking Framework, Apr. 2019.

[45] S. Acar, C. Burnett, and J.F. Cabra, "Ingredients of Creativity: Originality and More," Creativity Research Journal, vol. 29, no. 2, pp. 133-144, 2017, doi: 10.1080/10400419.2017.1302776. 